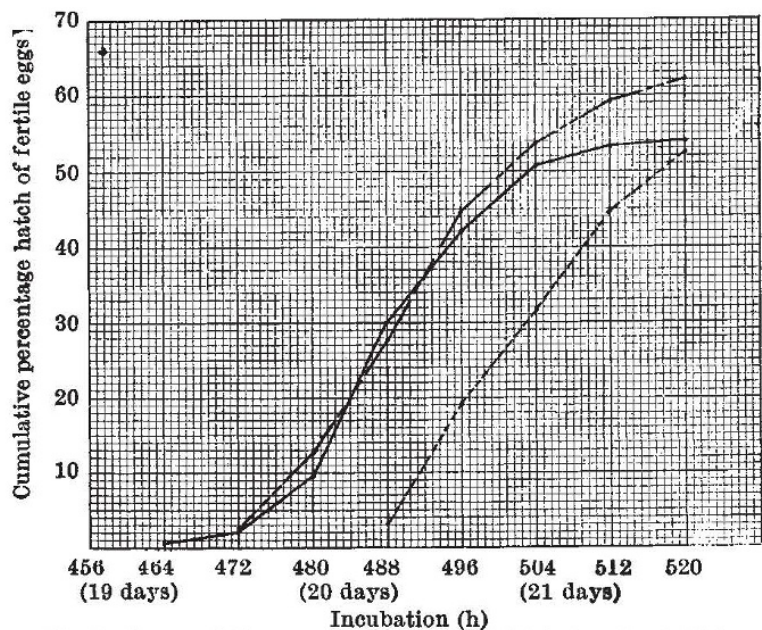

Fig. 1. Accumulative percentage hatch at 8-h intervals of chicken eggs exposed to different lighting treatments during incubation (Exp. 2). - continuous incandescent; $-\frac{1}{\text { coloured; }----, \text {, dark }}$

incubation and continued through $520 \mathrm{~h}$. Chicks which were completely free from the shell were removed at the various periods. Apart from lighting variations, standard incubation procedures were followed.

The cumulative percentages of chicks hatched from the different treatments based on percentage hatch of fertile eggs at each period in experiment 2 are presented in Fig. 1. The lines on the graph represent 540,180 , and 180 eggs for the incandescent, coloured, and dark control treatments, respectively. Some of the eggs exposed to continuous incandescent light were hatched after $464 \mathrm{~h}$, which was $24 \mathrm{~h}$ before any of the control eggs and $8 \mathrm{~h}$ before the eggs exposed to coloured lights. There were no differences attributable to colour of light; therefore, these three treatments were grouped together. Eggs exposed to the continuous incandescent light hatched approximately $16 \mathrm{~h}$ earlier, on the average, than those incubated in darkness throughout the experiment.

The differences observed in the third experiment were more pronounced than in the second experiment (Fig. 2). The lines on the graph represent 540, 180, and 540 eggs for the incandescent, coloured, and dark control treatments, respectively. The difference in hatchability was attributed to the difference in time the eggs were stored prior to incubation; in the second trial they were held 2-4 weeks and in the third trial 1-3 days before being placed in the incubator. The

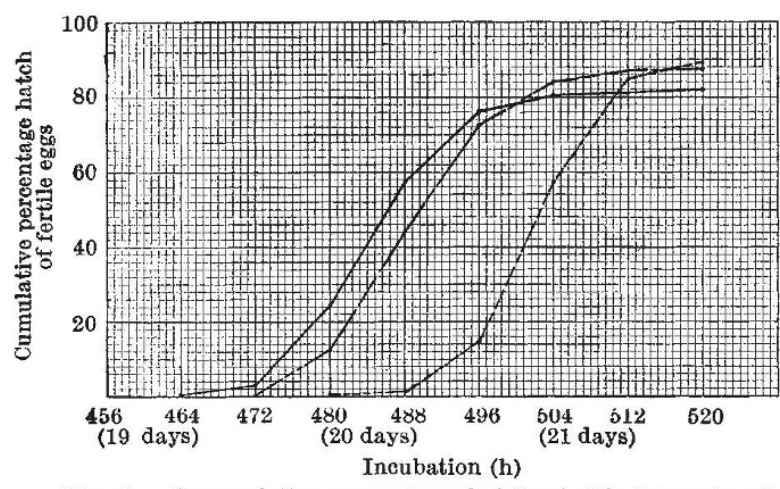

Fig. 2. Accumulative percentage hatch at 8-h intervals of chicken eggs exposed to different lighting treatments during incubation (Exp. 3). - , Continuous incandescent; - - - lower hatchability observed in the second experiment was therefore attributed to the age of the eggs ${ }^{5}$.

More variation in hatchability was observed among the ncandescent light treatments than the controls, but this difference was not statistically significant.

The radiant energy in the incubators where light was used was measured. Low readings were obtained on 20-25 per cent of the eggs which were closest to the light. The eggs not directly under the lights did not receive enough radiant energy to register on the instrument. The readings obtained (g.cel $/ \mathrm{cm}^{2} / \mathrm{min}$ ) were $0-0.1,0-0.2,0-0.1$ and $0-0.2$ for the yellow, red, blue and incandescent light, respectively. No differences were observed in hatching time that could be correlated with position of the eggs in the hatching trays.

The chicks from the second experiment were maintained in battery brooders for two weeks and no differences in viability were observed. The detailed procedure and spectral analysis of the coloured filters are available from me (J. V. S.).

$$
\begin{aligned}
& \text { J. V. SHUtZi } \\
& \text { J. K. LaUBER } \\
& \text { M. Kato* } \\
& \text { W. O. WILson } \dagger
\end{aligned}
$$

Department of Poultry Science,

Washington State University, Pullman, Washington.

* Present address: Zoological Institute, University of Kyoto, Japan.

$\dagger$ Present address: Department of Poultry Science, University of California, Davis, Calif.

${ }^{1}$ Jensen, L. S., and Matson, W. E., Science, 125, 741 (1957).

2 Lauber, J. K., Shutze, J. V., and McGinnis, J., Proc. Soc. Exp. Biol. and Med., 106, 871 (1961).

shutze, J. V., Matson, W. E., and McGinnis, J., Poultry Sci., 40,

CFunk, E. M., Missouri Agric. Exp. Sta. Bull. 341 (1934).

- Landauer, Walter, Connecticut Agric. Exp. Sta. Monograph 1 (1961).

\section{Movement of Salmon}

Is June and July, 1962, 156 'clean' salmon Salmo salar L. caught at sea by drift nets off the North Mayo coast were marked with a Lea's hydrostatic tag and released at once. One of these (length $65 \mathrm{~cm}$ ) released on June 29 was recaptured on July 28 near Ängelholm in southern Sweden, having travelled a distance of more than $1,750 \mathrm{~km}$. While a number of Irish tagged salmon have been recovered in Great Britain, mostly in Scotland, this is the first occasion on which a recapture has been made in Continental Europe.

Fisheries Division,

Christopher Mortarty

Department of Lands, Dublin, 1.

\section{Drosopterins in the Throat-Fans of Some Puerto Rican Lizards}

Two major groups of pigments were discovered recently in the throat-fans of Puerto Rican lizards of the genus Anolis $^{1}$. Yellow carotenoid pigments were extracted with organic solvents. In addition, a family of highly fluorescent pteridines were readily extractable from the dewlaps with aqueous solvents. Only colourless or faintly buff-coloured pteridines were detected in those species of Anolis the throatfans of which appear yellow or white. But in those anoles with orange- or crimson-coloured dewlaps (such as $A$. pulchellus and $A$. cristatellus) three prin- 